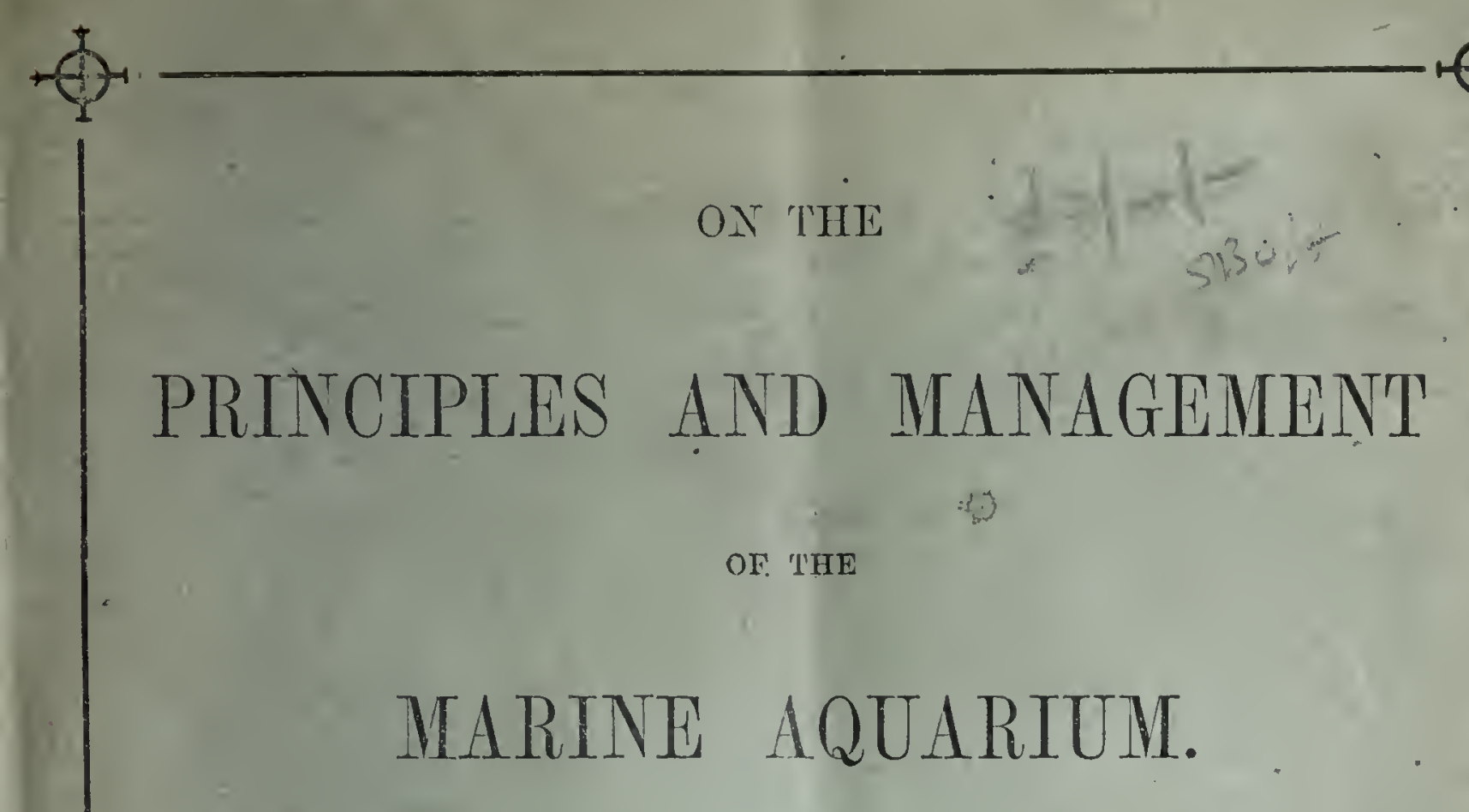

A PAPER READ BEFore the

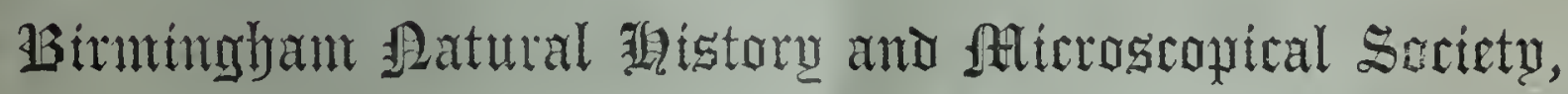

AT THE MIDLAND INSTITUTE,

ON. TUESDAY, 27 th JANUARY, 1874

$\mathrm{BY}$

W I L I A R . HUGHES, F.L.S.,

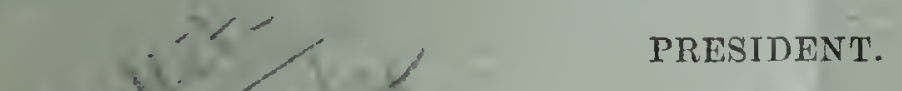

BIRMINGHAM :

CORNISH BROTHERS, 37, NEW STRER.

WATSON AND BALI, PRINTERS, CASTLE STREET.

$$
1875 .
$$



ON THE

\section{PRINCIPLES AND MANAGEMENT}

OF THE

\section{MARINE AQUARIUM.}

$\triangle$ PAPER READ BEFORE THE

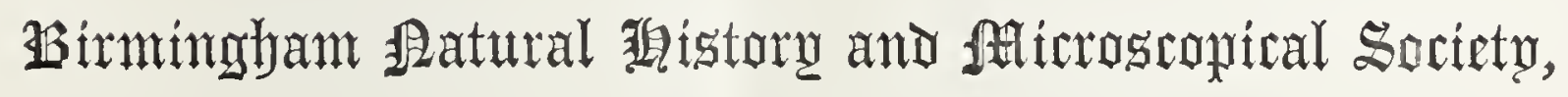

AT THE MIDLAND INSTITUTE,

ON TUESDAY, 27 th JANUARY, 1874

BY

W I L L A M R. HUGHES, F.L.S.,

PRESIDENT.

BIRMINGHAM :

CORNISH BROTHERS, 37, NEW STREET. WATSON AND BALL, PRINTERS, CASTLE STREET.

1875. 
Digitized by the Internet Archive in 2019 with funding from University of Toronto 


\title{
$\rho_{n}$ the Principles and Mandgement
}

\author{
OF THE \\ Marine Aquarium.
}

I appear before you as the author of a Paper this evening in compliance with the request of certain of the Members, made to me sone time since by the Honorary Secretary, that I would give some information as to the management of my own Aquarium; and because it has occurred to me that any particulars on the subject of Aquaria generally may be acceptable at the present time, when public attention has been directed to the establishment of a Marine Aquarium in Birmingham, the more especially as I have, since our last Soiree when I had the honour to introduce the subject, met many intelligent men in the town who have said to me, "Yes! a Marine Aquarium would be a capital thing for Jirmingham, but how should you manage about the water?" A very natural question, and one per se that is capable of a ready answer. Bring it by rail at the cheapest rate you can get it, as you would any other commodity that you require from a distance! But to my querists I fear this answer would by no means solve the difficulty in their minds, which is probably more deep-seated than appears on the surface-the popular notion of an Aquarium being in all probability derived from those antiquated glass vessels of globular shape and narrowed upper extremity (upon which it would be well if the Legislature imposed a heavy tax as a prevention of cruelty to 
animals) -in which gold and silver tish have been imprisoned, and the water has been clianged at more or less irregular intervals! My present purpose is to show, what those experienced in these matters are perfectly well aware of, that the water of a well-managed Aquarium needs to be changed no more than does the soil of one's garden in which are grown vegetables and flowers. It is, however, true that there is a loss of quantity by evaporation, and also a loss of some of the chemical constituents of sea-water, on account of the extraction of calcareous matter by tubeworms, crustaceans, \&c., which deposit it in constructing their coverings - as vegetables and flowers extract a certain amount of the original constituents of the soil, which may be replenished from time to time by natural or artificial means. 'Therefore the soil is simply a medium for the growth of plants-and the water in the Aquarium a medium for the preservation of animals. Beyond my own circle of friends and from those not members of this Society the yuestion may naturally arise-but what are your qualifications for giving an opinion on the subject of Aquaria?- the querists naturally inferring from my official position as Treasurer of your great Borough that figures and foraminifera-accounts and sea anemones-blue books and barnacles have very few affinities in common. It might be of little interest to this meeting to tell how upwards of thirteen years ago, I first directed my attention to the subject of Marine Zoology. But to me it is a very pleasant retrospect, and the names of kind friends to whom I am indebted for early instruction, such as Dr. Wade, Mr. W. Mattieu Williams, formerly of this Institute, Mr. Joseph Bragrg, and others, occur to my mind with grateful remembrance. Subsequently, when I had outstepped their teachings-succeeded those of Mr. P. H. Gosse, from whom personally and through whose writings I have derived the most valuable information and benefit in many ways, similarly, from Dr. Spencer Cobbold, and from Mr. W. A. Lloyd, of the Crystal Palace, Hamburgh and other Aquaria, whose great knowledge and experience have always been at my service during a period of twelve years, whenever I have sought his opinion. Throughout that time I have maintained in perfect health marine animals of great variety and beautysome of excessive rarity-for example the beautiful Vestlet Cerianthus 
Lloydii, (Edwardsia vestita) which figures life-like-thanks to the gifted pencil of my friend Mr. G. Sherriff Tye in the 1st part of the Transactions of our Society-and which is now I believe nearly extinct on the British shores. Regarding that beautiful order of Zoophytes the Actinoida (or sea anemones) I was quite surprised on looking over the Crystal Palace Hand Book of my friend Mr. Lloyd to find that at one time or other I had possessed twenty-four of the species (thirty) enumerated therein, and that, moreover, I had been fortunate in possessing three species not now in that Collection. It is not too much to say that I have exhibited to this Society at various times during its existence-and that of its parent-" the Birmingham Natural History Association "- a greater number of rare and beautiful marine animals than have been shown and described at any other inland Society, and I would fain hope with some little benefit to science. I do not mention this ostentatiously, but simply to give a practical illustration of what can be done by the Marine Aquarium even in a small way. The Aquarium has really an advantage over those beautiful little fairy-like rock pools at the sea coast-you can group together Animals of different localities which never can be associated together naturally-and you can examine them at your leisure in your own roon, and I venture to say that neither you nor your friends will ever tire of the examination. To me during these years, the Marine Aquarium has been a subject of intense interest, and an intellectual recreation of the greatest relief after official work, always of a laborious and responsible character.

The history of Marine Aquaria is interesting, and will repay perusal by all who feel inclined to consult Mr. Gosse's exquisite Book-"The Aquarium," or Mr. Lloyd's "Hand-Book to the Crystal Palace Aquarium" -a wonderful sixpennyworth of information that ought to be in the hands of every marine Naturalist. To our great townsman, the late Dr. Joseph Priestley, for lis grand discovery of the mutual dependence of plants and animals on each other, must be awarded the honour of its discovery. No matter in what Aquaria-fresh-water or marine-public or private-large or small-these principles govern them. The mode in which they are applied may vary greatly, but the 
effect aimed at is the same. The introduction of the Marine Aquarium as an object of public interest is however mainly, if not entirely, due to the delightful books of Mr. Gosse-a quarter of a century ago-which contain illustrations by his pencil so novel, beautiful, and truthful, besides being coloured after nature, that they have marked a new era in Zoological literature. The Marine Aquarium reached a fever of excitement in 1860-something like potichomanie or crochetwork-and appears, on Mr. Lloyd's authority, to have nearly died out in 1862, or to have been confined to a few enthusiastic amateurs-since which period, however, public Aquaria have steadily grown into favour.

To help us to arrive at a knowledge of the principles of the Aquarium we must first ascertain what it is. To Mr. Gosse we are indebted for the name Aquarium-as applied to a receptacle for plants and animals mutually balancing each other-and he discusses in his delightful book with that title, its propriety as such, being a word easily pronounced and easily remembered, significant, and expressive. Dr. Carpenter, and others use the term Vivarium-to which Mr. Gosse objects, as it lacks distinctness of meaning, literally being an enclosure in which living animals are kept, such as a park, a rabbit warren, or a fish pond, in which sense it was used by the Ancients. Sone authors have lengthened the term to Aqua-vivarium, to which Mr. Gosse also oljjects on account of its length and uncouthness. The word Aquarium is, therefore, in use popularly as signifying a collection of aquatic animals maintained in health by plants, or by artificial means supplying their place, "distinguishing it as a Fresh-water Aquarium if the contents "be fluviatile, or a Marine Aruarium if it be such as I have made the "subject of the present volume." * I venture to suggest the word Aquariist as the most convenient, if not the most correct, as applicable to one skilled in the management of the Aquarium. I do so, because the word Aquariologist is too long, and the word Aquarian is too indefinite, it has been, I believe, used in three senses; 1. By my friend Mr. Newman,

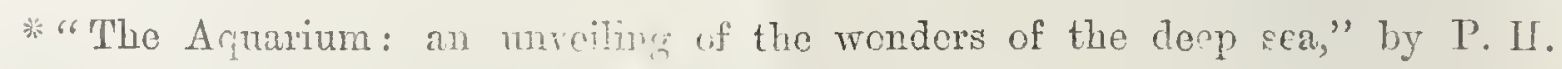

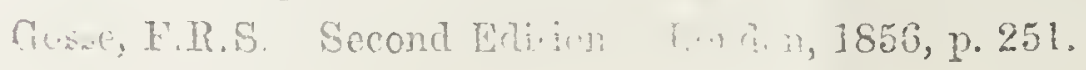


to a person who works at, or keeps an Aquarium; 2. By the Americans to a "water drinker," or "teetotaller;" and 3. By the early Christians, who used water instead of wine in the celebration of the Eucharist. Mr. Newman's definition, however, has priority to recommend its adoption if desirable.

Mr. Lloyd, in his book before referred to, which contains the most recent results of his large practical experience, describes the Aquarium as "an arrangement for the maintenance of living animals, "under the following three conditions," viz.:-

"1st. The water must not be changed, though it may receive "addition from time to time of whatever it may lose, as, for instance, " in fresh water by evaporation, or in such solid matters as are taken "from it in the course of the formation of the shells and other hard "parts of creatures existing in it.

" 2 nd. The water must be kept not only in a pure and respirable "condition by its absorption of atmospheric air at its surface, which "absorption may or may not be increased by putting the water in "motion in any convenient manner, but this purity must be assisted "by the presence of vegetation growing in it, and tending to decompose "the poisonous carbonic acid gas evolved from the animals, such vege"tation taking up the carbon of the gas into its own substance, and "liberating the resulting oxygen for the use of the creatures.

"3rd. The Animals must not be lung-breathers, that is to say, they "must be either such as the sea-anemones and corals and some others "which have the function of respiration diffused over their entire "bodies; or, be such as the creatures above them (up to and ending "with fishes), which are provided with gills during their whole period "of existence. As lunged animals do not require the purifying pro"cesses just alhuded to, an Aquarium is not for their use, and they are "therefore excluded from it; and this exclnsion applies even to such "aquatic animals as water hizards, frogs, and salamanders in their adult "states." "*

Exception may be taken to the third of Mr. Lloyd's propositions because the adnission or rejection of hung breathers in no way interferes

* "Official Hand Book to the Marine Aquarium of the Crystal Palace Aquarium Company (Limited)," by W. A. Lloyd. Fourth Edition, 1873, 117. 7, 8. 
with the balance of the Aquarium, and it is, therefore, a mere matter of opinion. The presence of an aquatic mammal in an Aquarium sufficiently large for its accommodation would, it seems to me, be somewhat analogous to the position of a ship sailing over the sea. The motion of the ship would, to a feeble extent, aerate the water by disturbance of its surface-the mammal, by its swimming in the Tank, would mechanically contribute to the same effect in, of course, a greater degree, but so far as chemical action is concerned, it could not have the slightest influence either in maintaining or disturbing the balance. Those who saw the first porpoise in the Brighton Aquarium will doubtless remember, that in the large Tank in which it was confined there were a number of conger eels, which of course supplied the "animal balance," and therefore the presence of the Manmal was not essential to, and in no way interfered with such balance-and moreover, there was ample space for its accommodation without interfering in any way with the congers, which generally rested at the bottom of the Tank. Bearing, therefore, these poirts in mind, and even admitting that an Aquarium is, according to Mr. Lloyd's third proposition, a halitat solely for Marine or Fresh-water animals not being lung breathers-and supposing it is determined to keep lung breathers as well-such as porpoises, dolphins, \&c.- - surely they must be maintained in vater which for all practical purposes will be an Aquarium, although not strictly answering to its original but perhaps restricted name, and for reasons already stated it is not desirable to change that name-rather then let it be more comprehensive and admit where practicable) animals of higher organisation, such as those referred to. I, therefore, in common with Mr. Newman, agree to differ with our friend, and consider the managers of the Brighton or any other public Aquarium are, without involving the sacrifice of the name Aquarium, or violating the law that governs it, perfectly justified in introducing a porpoise, or other aquatic mammal, if they can secure and maintain it alive, and exhibit it to the public as an object of interest, or, what is more important, derive from it information on any point of scientific value. How and by what means the other important propositions involving the perpetual chain of evolution of one gas 
by one series of life, and its absorption under modified conditions by another series, it in its turn giving off in exchange the life constituents necessary for the first, and thus constituting the balancing principle of the Marine Aquarium, are to be successfully carried outI will try and explain,-very briefly on this occasion, and so far as our present knowledge permits-for the limits of a Paper of this description will not allow of very elaborate detail.

I venture to define an Aquarium in its liberal sense, as being a vessel of some kind for marine or fresh-water animals to live and move in, under conditions where a sufficient amount of oxygen is supplied naturally or artificially for the existence of such animals, whether it be in the case of the simpler forms of life, such as sea-anemones which respire over the whole surface of their bodies, or animals of higher organisation where the organs of respiration are differentiated, as fishes, which respire by means of gills; or mammals which breathe by means of lungs; such mammals absolutely requiring water as a means to move in,- - and coming to its surface to obtain oxygen from the surrounding atmosphere necessary to breathe in. The three subjects to bear in mind in their order of importance, influencing the above conditions, are light, aeration (which implies circulation), and temperature.

The recent researches in deep-sea dredging although they have cleared up many most important points as to the geographical distribution of marine animals-pressure-currents-temperature, \&c., of the sea, and have inaugurated the wonderful doctrine of "the continuity of the chalk," have left us still in much obscurity about that mighty question light, and its effects on marine life. The latest accounts record instances of animals composed almost wholly of eyes-while others indicate the total absence of such organs in other animals! Phosphorescence may at great depths compensate the absence of light, for we read* that at a depth of about 600 fathoms-off the South East coast of Ireland--." Many of the Animals were most brilliantly "phosphorescent, and we were afterwards even more struck by this "phenomenon in our Northern cruise. In some places nearly every" "thing brought up seemed to emit light, and the mud itself was

\footnotetext{
* "The Depths of the Sea," by Professor Wyville Thomson, F.R.S., 1873, p. 98,
} 
"perfectly full of luminous specks. The Alcyonarians, the brittle-Stars, "and some Annelids were the most brilliant. The Pennatulee, the "Virgutarice, and the Gorgonice shone with a lambent white light, "so bright that it showed quite distinctly the hour on a watch; whilst "the light from Optriacantha spinulosa was of a brilliant green, "coruscating from the centre of the disk, now along one arm, now "along another, and sometimes vividly illuminating the whole outline "of the star-fish."

It is certain that liglet is the primary question to be considered in relation to Aquaria. The presence of it in an uninterrupted volume combined with a high rate of temperature, may in a few days convert an Aquarium which was in an efficient condition of health and beauty of the inhabitants, into a decomposing mass. It must be borne in mind, however, that light alone without a high temperature cannot cause decomposition in an Aquarium. Excessive light causes an excessive development of Algæ spores, which make sea water and even fresh water opaquely green, but that does not interfere with the health of the animals. When the temperature is above $40^{\circ}$ light must bo used sparingly, and adjusted as to quantity and quality. The direct rays of the sun should never be allowed to converge on an Aquarium, especially if they proceed from a point, in which the south and west rays predominate.

Figure 1 represents a glass Tank transparent on all sides-placed in a conservatory-with the rays of the sun in this objectionable manner. The situation is objectionable, the light and heat are objectionable, the vessel is objectionable. They illustrate the extremes to be avoided-because in addition to the great heat directed upon the Tank-the growth of vegetation will be too excessive-no part of the Tank will be free from its development. It is a "false balance."

Figure 2 represents in a far less objectionable manner, a lateral form of illumination for transparent, and still less for opaque Tanks, the dotted lines in the figure representing the passage of the rays of light, which in the former case would pass through, as at the dotted lines A B-and although the light in these instances may be right from a point in which the north and east rays predominate-the form of the 
vessel is baul, espectilly in the tramsparent one, where the rays pass through it, as it offers too large a surface for the reception of light, and the consequent excessive growth of vegetation is promoted.

Figure 3 represents what my experience has proved to he the most effective, viz: the slope back lark chamber Tank which I have had in constant use upwards of twelve years, invented, I believe, by Mr. Edward Edwards, late of Menai Straits, but now of Chester, (whose, beautiful and successfully managed Aquaria you will remember I had the pleasure of describing to this Society in the Autumn of 1868) and which was manufactured by Mr. Lloyd. In it there is a minimum space for the reception of the rays of light. It consists of slate and glass. The dimensions are about 22 inches long, by 18 inches wide, and 9 inches high. Its capacity is about twelve gallons. Three sides are opaque-the fourth (of glass) transparent. It is, therefore, viewed horizontally from the room in which it is placed, which is its best aspect for the examination of the inhabitants. But of course it permits of vertical observation in addition. The dark chamber is intended to hinder the excessive formation of the spores mentioned at page 8, but it does not prevent the formation of vegetation on the rockwork, \&c. It contains a shelving platform, on which are piled masses of rock work up to the top of the inclined surface, and thus the animals can select depths of water most agrecable to them. The dark chamber at the back excludes the mass of water therein from the light, thus keeping it cool and free from vegetation, but there is a free circulation between this and the main body of water in the Tank, artificially assisted as hereafter described. Moreover, the rays of light coming from a north-easterly point, (which is the best aspect for an Aquarimm, and which is the position in which mine is placed)-in a slanting direction parallel with the platform, enter the water at its surface only. Any other mode of illumination is bad-and experience during twelve years has demonstrated to me, in maintaining rare and delicate animals, that this form of Aquarium for private purposes is the best of all. This arrangement is not necessary in public or other Aquaria provided with streams, because separate reservoirs, such as that the Crystal Palace possesses, form in themselves the dark chambers. 
Any Aquarium niay be exposel to great light and may be unprovided with an amexed dark chamber, and yet it may act well, if it has a separated reservoir underground of four or five times the capacity of of the Aquarium, with which it is in constant and sufficient communication.

As to aeration, it follows-the larger the surface of water exposed to the atmosphere the larger amount of oxygen will be absorbed. Mr. Lloyd justly says that-" the value of water for Aquarium pur"poses does not within certain limits depend so much upon the bulk "of it as upon the advantageous distribution of that bulk over large "spaces."

Figures 4 and 5 represent two Tanks or vessels of equal capacity - the contents of each being 1,000 cubic inches. The depth to the water line as shown by the dotted lines respectively is in No. 55 inches; and in No. 4 -20 inches. The surface water in contact with the atmosphere is in No. 5, 200 square inches, and in No. 4, only 50 square inches. Therefore the absorption of air is in No. 5 four times as much as in No. 4. Again, if the surface of No. 5 is smartly agitatect for a few minutes, the whole column of water is exchanged-but the time necessary for this exchange would in No. 4 be quadrupled. Therefore No. 5 would, accommodate twenty animals in health, against a fourth of that number in No. 4. These figures are copied from Mr. Lloyd's first book, published in 1858,* and have been lithographed for me by Mr. G. Sherriff Tye, to whom I record my obligation, as also for the other five original drawings.

The Tank which I have mentioned, permits in a greater degree this mode of aeration than any other. With healthy plants growing in it, and balancing the animal life it needs but a minimum of attention. All that is required being the breaking of the surface, so as to change the water in contact with the atmosphere, and prevent the accumulation of a film of dust. This "breaking" is effected by means of a pair of boxwood forceps about seventeen inches long, as at Fig. 7. The forceps are held firmly and passed rapidly through the water for a few minutes until the whole mass has been disturbed, and bubble-like

* "A List of whaterer relates to Aquaria," by W. A. Lloyd, London, 1858, p. 130, and Supplement to the same, 1860. 
froth in which atmospheric air is entangled appears on the surface. This mode is preferable to syringing or such like operations. These latter disturb the stratum of shingle at the bottom of the Tank, and do not effect an equal distribution of the air introduced; besides, the piston of a syringe soon becomes objectionable in odour, and unfit for use. My observations under this head, will explain the reasons expressed in all earlier part of my Paper against the fish globe shape for Aquaria, where the surface is narrowed and contact with the atmosphere lessened. For those who do not care to invest in a Tank, a nice little Aquarium, Fig. 6, can be lad for a few shillings. Obtain a confectioner's cake glass of about 13 or 14 inches diameter and 6 or 7 high — of flint glass free from flaws, have a pedestal stand turnced for it of some hard wood with an aperture for the knob to lit in; and; although you will have some trouble in the adjustment of the light, still with care you may outain some very good effects, and maintain for a long time many marine Aninials of the radiate type and even small fishes in excellent health. It cannot, however, be considered a model Aquarium.

Paint is excessively injurious to the inmates of an Aquarium, and wherever painting operations are going on, the Aquarium should be removed to another room away from their influence. Miss Stephens, of Bridport, who has had considerable experience in the managenient of Aquaria during many years, informs me that the contents of an Aquarium exposed to the influence of an atmosphere impregnated with paint, were entirely destroyed from its injurious effects, and I rementber a similar case where a rare fish was killed from the effects of varnish used after painting, which caused a scum to appear on the surface of the water, interfering with proper aeration, and thus the fish was poisoned.

If the Fishes seek the surface of the Aquarium constantly-or refuse food at the usual time-if the Anemones reject food-or protrude the walls of the stomachal cavity-or abnormally elongate the column-or detach the base from the rockwork and lie about loosely -these are bad signs, indicating local decomposition, overcrowding, or the effects of insufficient aeration, and the evil must be at once sought out and remedied.

The common anemone of the coasts (Actinia mesembryanthemum) is, I believe, the best indicator of the healthy state of a Tank, as it 
refuses to expand when the water is in an insufficiently aerated condition, or too dense from an insufficient supply of fresh water.

The higher the organisation of the Animal the greater is its breathing capacity - therefore in public Aquaria, where fishes are maintained, a fiee circulation of water through the Tanks, seems to me in the absence of a full complement of plants a necessity to obtain perfect aeration, and without it I do not see how they can be properly conducted. Where practicable, Otto and Langen's gas engine appears the most effective, economic and compact notive power than can be used to provide continuous circulation. Tides, winds, storms, plants, all contribute to the aeration of the sea, and all our contrivances are only endeavours to imitate the effect of the operations of these agencies.

As to temperature-this is a very important subject in connection with Marine Aquaria-apprehended more clearly perhaps when it is known that the temperature of our Seas within the depths from which we obtain most of the animals adapted to exist in Aquaria, only exhibits a range of about 25 degrees, between $40^{\circ}$ and $65^{\circ}$ Fahrenheit, whereas our atmospheric temperature varies enormously. I am informed that in Britain the lowest recorded temperature in air in the shade is $-7^{0}$ Fahrenheit, and the highest in air in the shade is $93^{\circ}$ Fahrenheit - or a range of 100 degrees Fahrenheit. Consequently it is most Aesirable that the former range $\left(40^{\circ}\right.$ to $\left.65^{\circ}\right)$ shall be maintained. The water in the Aquarium should always be cold to the hand, let the temperature of the atmosphere be wliatever it may. Placed in a north or east or north-easterly position, as I have stated previously, and in a room well ventilated, and that has ordinarily in cold months a fire burning in it, there is little to be feared. Extreme cold, although sometimes fatal to animals of the radiate type, is not accompanied by rapid decomposition, on account of the low temperature prevailing, and it may be nıodified by placing over the Tank at night a newspaper, or covering of some non-conducting material. At other times the Tank should not be covered, but exposed to the free play of the atmosphere. The danger is greatest when almost tropical heat suddenly sets in during the summer months. At this time the patience of the Aquariist will be tried-but by frequent ventilation of the apartment-by shutting off light by means of a Venctian or other blind-by the introduction of a piece of ice once a day, and above all 
means by not overcrowding the Aquarium with animals, one may jull through even the "dog days" with success. It is desirable here to mention that it is a great mistake when a Tank is going on well to add to its stock. Refuse your friends' present courteously but firmly, and do not be tempted under any circumstances to accept the responsibility of a "white elephant."

Respecting the management of the Marine Aquarium, which is purely practical-the good old proverb, "cleanliness is next to godliness," is eminently applicable. If we regard the Aquarium in the light of a Sanitorium or House of Convalesence, which is a convenient mode of fixing upon one's mind the necessity for the greatest amount of purification naturally and artificially to be always carried on, we shall instinctively manage it with this object in view, never introducing anything impure, or in even a state of semi decomposition, removing such if liscovered, and being careful to aerate the water and purify whatever was near the decomposing substance. Do not, however, think that this is a tedious and harassing process. It is nothing of the kind. Ten minutes a day-fire at night and five in the morning-are quite sufficient for all the necessary work needed.* Mr. Lloyd very justly says in his Hand rook before referred to"that the reason why Aquaria in private hou es have met with such "small success may be found in the natural clifficulty of the whole "thing; in the general want of a knowledge of Zoology among those "attempiting it; and in the difficulty of producing an at once "sufficiently comprehensive and practical manual of instructions on "the subject. General laws can only in such cases be stated, " as it is not possible to give any definite rules, applicable under all " circumstances, respecting the kind, sizes, and number of animals "which may be permanently kept in a given quantity of water, inas" much as the capability of the water for maintaining the animals in a "private house (and even in a building specially made for Aquarium "purposes), is liable to continual change from various circumstances, "among which temperature is a principal one, and regulation of light "is anotlier. Such capability is also greatly affected by the propor"tions of the vessel containing the water, for if the fluid is spread out 
" in shallow masses, its absorption of air by mere surface contact with

"it, and its consequent good condition is much greater than when it is "piled up (so to speak) in tall masses with small surface area."

Undoubtedly a stream of water, intermittent or continuous, accompanied by means for introducing an abundant supply of air to the Aquarium are best adapted to produce the most successful resultsif one considers for a moment the general character of the inhabitants of a stagnant pond in which live eels, tench, and carp, and that of a clear torrent-like river where live trout, salmon, and grayling, one gets a tolerably good notion of the superior effects of this mode of oxygenation. But this is scarcely practicable without much expense in a private Aquarium, although to my mind, as already stated, absolutely necessary in public Aquaria. By a private Aquarium I mean one maintained in an ordinary dwelling house. Nevertheless, by the careful adjustment of the balance of the relations of animals and plants-by agitation of the surface for a few minutes at night and morning, so as to allow no film of dust to accumulate or interfere with the free play of air over the surface, we may get in some degree a substitute-though animals of high organisation as fishes cannot be maintained so successfully as in public Aquaria. On the other hand, animals lower in the series of classification, such as sea anemones and other radiates and crustaceans may be main-tained for many years. Indeed, there seems no limit to the life of some of them. The celebrated Actinia (a variety of Actinia mesembryanthemum, I believe) once the property of Sir J. G. I)alyell is now stated to be in its forty-fifth year of captivity in Edinburgh, has given birth to over a thousand young ones, and shows no signs of getting old !

I propose to deal with each portion of the Aquarium establishment and management separately. Assuming that a suitable Tank has been selected, and that the errors alluded to in the former part of my paper have been avoided, we first consider the rockwork. Experience has demonstrated that for such purpose nothing is so suitable as Mica schist, its compact non-friable character offering a favourable nidus for the growth of vegetation. Moreover, its dark green hue has an agreeable effect under water, and exhibits the colours of sea-anemones, tubeworms, and fishes to advantage. Animals readily adhere to it, and I 
have in my Tank instances of a tube-worm (Serpulu triquetic) tro inches in length, that have developed upon it from germs contained in the sea water. The mica should be of picturesque fracture when broken up, and should first be cleansed in fresh water of impurities, and cemented on to the sides and back of the Tank, with none but the best Portland cement, finely sifted. After it has well set, fresh river or rain water should be introduced and allowed to remain, until all impurities and opacity from lime and other causes have subsided. After this, it should be rinsed over with sea water before the stuck of sea-water is introduced. The mode of displaying the rockwork must be left to the taste of the Aquariist. I would, however, recommend the avoidance of too many deep crevices, wherein animals may lurk and die unsuspected.

Next comes the slingle. As a relief to the dark green of the rockwork, and as acceptable for animals, such as the Echinus (Seaurchin) to burrow in, nothing is better than the finely-ground masses of flint about the size of large peas, found at Shanklin, and on some other shores of the Isle of Wight and Southern Coast,-its pale brown or buff colour is very suitable as not militating against the colours of the inhabitants of the Tank. Sand is not recommended. But few Marine animals suitable to be kept in private Aquaria are found burrowing in sand. Moreover, it is apt to get covered with a filmy mass of vegetation, very difficult to dislodge, and the removal of the sand from a Tank when requiring to be cleansed is a troublesome process. Sand is chiefly objectionable in currentless Aquaria, because it lies close, and hinders oxygenated water from circulating among it, whereas shingle has interstices admitting water. Before any shingle is introduced, it should be carefully cleansed of all shore impurities, and this is best effected by washing it in a vessel such as a domestic colander, free from any particle of grease, placed in a tub, under a water tap, when all impurities will float away over the surface. Like the rockwork it should be rinsed in pure sea water, before being placed at the bottom of the Tank, which it may cover to a depth of two or three inches.

The water. If possible all sea water for Aquaria should be procured during the winter months, as at this period it is freer from germs 
of life, both animal and vegetible, and absorbs a greater quantity of oxygen at the surface than at other times. If taken in the hot summer months when Medusce and Noctiluce are floating about towards the surface, decomposition is often the result. It shoull be taken when the tide is coming in-a mile out in the open sea, in the morning if possible, and care should be had that the vessel (such as a Bristol stone jar, or glass) in which it is conveyed is perfectly clean, and that even the cork is a new one. A bad cork has often spoiled a bottle of wine -much less has spoiled a bottle of sea water! No sea water should be taken along shore from such places as Liverpool, Rhyl, \&c., where rivers flow and dilute the standard quality, but the preference should be given to Weymouth, Torquay, Tenby, \&c. It should be of high specific gravity, so that one gets the largest amount of saline constituents for the smallest sum of money. The water should be kept securely corked in a cool dark place, and when wanted, carefully syphoned into the tank, so that no sediment which may exist may be introduced with it. By all means keep in reserve a six gallon jar of pure sea water. It will be found useful when specimens are received, and have to be temporarily accommodated before being finally located in your Tank. All Aquariists should have a store of sea water under all circumstances-"Old store, no sore." The standard of the water must be maintained. Its specific gravity is about $1,026^{\circ}$ at $60^{\circ}$ Fahrenheit. Sea water is less dense at a higher than a lower temperature. Evaporation goes on constantly, but this can be supplied by the introduction of distilled, or pump, or river water. I give the preference to distilled water, as it is freer from germs that may develop injuriously from river or pump water. The fresh water should not be introduced too rapidiy, but a little sea water should first be taken out-a cuart or so-and mixed with an equal quantity of fresh water, and this should be gradually introduced and well agitated with the mass of water in the Aquarium so as to uniformly dilute it. Any deviation in the standard may be observed by a hydrometer, or by two small glass balls (of different colours) acting in concert-one floating at top, and the other remaining at the bottom of the water-when their conditions will vary with the strength of the sea water-or what is as 
ginul as anything by " rule of thumb" mark on the Tank the nommal licight of the water, which should be correct at introluction, and licep it to the standard as before stated. A large public Aqurium or a small one if there are corals, or echinoderms, or crustaceans or fishes, may require to be occasionally suppliel with embonate of lime, to comprnsate the quantity abstrated from the water by animals of these classespersonally, however, I have never had occasion to use it. There is as a rule more dang to be feared from sea water becoming too sult by evaporation, than by the accilental introduction of too much fies:? water. In the former case you have a brine or pickle, in the latter a dilution that will in time right itself. In a private Aquarium there is a certain loss caused by the slopping over of the water and by periodical cleansing and other causes, smill but appreciable, which must bo supplied from the stock bottle. In other respects there is no lussfor you may almost entirely evaporate the fluid from a given quantity of sea water, leaving scarcely anything lut its saline constituents, and afain return it to its nomal state by the introduction of fresh water. If from any causes sea-water becomes putricl, exposure of it to the oxygenating effects of the atmosphere, in shallow vessels, and occasionally breaking the surface as previously directed, will soon restore it to its original condition. I have found that if at the bottom of the Tank there is an accumulation of sedimentary matter it is a good plan to draw off several gallons with a syphon (a few feet of $\frac{3}{4}$-inch Indiarubber tubing) from the bottom, and allow it to settle in separate ves. sels for a few hours, and then return it carefully to the Tank again. A glass dipping iube about ten inches long by a quarter of an incle diameter is very useful for the removal of decomposing substances. Much has been said about artificial sea water, but my experience is not favourable to it-I found it crule and harsh in its effects on the anemones, they refused to expand, and shrank up and died. Should any of the Members desire to malie a trial of artificial sea water I append Mr. Gosse's formula." I have been informed that if kept in a

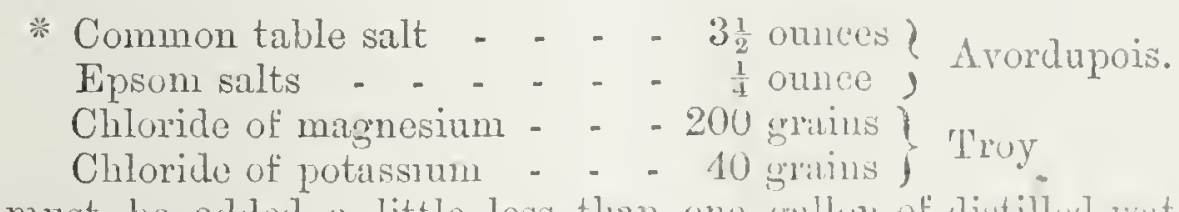

to which must be added a little less than one gallon of distilled water, so kle t a specille gravity bubble $1,02 C^{\circ}$ will juzt sink in it. 
conl place for some months and the constituents allowed to blend well tngether, that on exposure to the air the ordinary conferva found in an Aquarium will develop in it. As pure sea water can readily be obtained from the coast at a few pence per gallon, I prefer the genuine article. Artificial sea water, however, needs trial on a large scale in England.

The various accessories of the Aquarium being supplied, now comes the question of vegetation. My experience has demonstrated that if the Tank is established in the autumn and a few pieces of rockwork introrluced on which are growing fronds of the sea lettuce (Ulva lutissima) Spores will be given off from these plants which, finding a favourable nidus in the Mica, develop in the early spring months into healthy and vigorous vegetation, which will continue until autumn again. As soon as the young plants exhibit signs of development the old ones must be removed. It is not possible to describe the beauty of this vegetation. Even without animals (if it could exist) it would be worth maintaining in an Aquarium. Of brilliant grass green colour, and of the richest spring tinge, the young Algce appear like broad short blades of young wheat plants, gently waving sometimes with the agitation of the sea water, and seeming, when undisturbed, like a bank of lovely green moss. From this under the stimulus of the early morning sun during a brief period, globules of oxygen (like silver) rise to the surface, and disperse in myriads. It is a truly beautiful sight-one of the most interesting I have ever witnessed in comnection with Aquaria. I have known fronds of between two and three inches in length develop in this way. Now, if fishes are maintained in the Tank this vegetation is highly serviceable as foud for them. I have seen my fishes,-grey mullets and wrasses,-bobbing at the vegetation for half an hour together, and I have seen the blennies tugging at it, as a bird does at a worm when making its escape into the ground. There is another great advantage connected with this form of growth, it neither attacks the slate sides of the Tank, nor the glass, nor the shingle-their smooth surfaces probably presenting no nidus or resting place for the spores. I believe it is here for the first time demonstrated the great advantages arising from the introduction of Ulva at this particular time of the year, when the surfaces of the rockwork are alosolutely free from any other form of vegetation, and where other 
plants are not present to lear to a "struggle for existence" - three most important points. The delicate filamentous red sea weed Grifithsice setacea is very beautiful as an ornament, but of not much practical utility - and I have not found that young plants are developed by the introduction of it. Mr. Gosse's remarks on the growth of sea weeds in Aquaria (Aquarium, page 276) should be read by all interested in this subject. But while on this subject I do not maintain that the autumn is the only time of the year when a 'Tank may be established. It certainly can be set up at any time, but, so far as my experience has shown, if established at any other period and without the introduction of fronds of U/ra latissima, an inferior form of vegetation is the result. 'The silky grenish black filannentous conferva (ipirulina and Oscillutoria) spring up with marvellous rapidity in hot months, covering rockwork glass and shingle, and jroving most diffeult intruders to dislodge. In fact they cumnot he thoroughly exterminated without a regular scouring process, involving much time and trouble. Mr. Lloyd says that conferva, like fire, "is a good servant but a bad master." Its growth may be checked by the absence of light and by rubbing the sides of the Tank and the glass front with a sparle-shaped cleanser, such as that given at Fig. 8, covered with folds of lamp cotton. Mr. Lloyu speaks most highly of that important and effertive vegetable scavenger Huliotis tuberculutu (the Ormer), and states that no scrubbing is needed where it is, and where the light is not in great excess. Mr. G. Sherriff Tye, who has had much experience in the mungement of the marine Aquarium, recommends Troctus umbilicatus, Littorina littorea, and Patella vulyata as good scavengers for a small Tank, and thrive well when Huliotis could not be kept by reason of its large size.

If the suggestions I have enumerated are carried out, the water in the Tank will be brilliant and sparkling,-clear as crystal, very different from stagnaut water, such for instance, as that which has been recently boiled and cooled, or which has been allowed to stand in a tumbler or water bottle for a day or two, in the absence of light and vegetation. It will have life in it, so to speak.

And now we come to the consideration of a very important question-the introchuction of the mhabitents of the Tink, which shouhl 
The done aftar there is a growth of regetalion. It is not possille to grive very specific directions-so nuch depends upon the size, position, and healthy state of a Tank. As a rule, howerer, the higher the organisation of the animal, the larger the space required for its maintenance-for instance, a dozen anemones may be maintained in a space which would only accommodate four of the smaller crustaceans, such as shore crabs and prawns, or one fish not more than four or five inches in length. But what would apply to a low temperature in the winter months, would not hold good in weather when without much warning tropical heat suddenly sets in. Regard must also be had to the locomotive or stationary habits of the animals introduced. Tagrants are more difficult to maintain than settlers. A brief acpraintance with the principles of Zoology will do more to aid the student in the management of an Aquarium and the association of the various inliabitauts of the Tank than anything, and will familiarize him with the kinds of animals that may be associated together with advantage.

As to fceting. All marine animals require food to be given them and if this is nots attended to they will not survive long or thrive in the Aquarim, howerer well regulated it may be as respects the mutual balance of animal and regetable life. A well-managed Acpuritim, with the water mohranged, fosters the reproduction of minute marine life, such as Infusoria, Entomostraca, \&c., upon which all the inlabitauts of a Tank will feed naturally, and some, such as tube-Troms and pipe-fishes, exist solely on this nutriment. We do not know upon what the Holothuriadee (sea-cucumbers), and other rermiform echinoderms feed, as sand is usually found in their stomachs. Such animals, however, as the sea-anemones, the star-fishes, the carnivorous mollusen, and most fishes require to be fed artiticially. This may be performed not less than once, or more than four times a week, according to the temperature, taking care that an excess of culbonic-acil gas is not giren off by the animals by a too abundant supply of food, which excess is of course more likely to arise in the summer month. For artificial food which should be varied, I recommend uncoulied fresh fish, such as hakluck, whiting sole, or suiclt - any fish in fact 
that 'contains but little oil or fatty matter. Oysters are gond, hut too expensive now-a-tays! Give mussels but rarely, as they have an enervating tendency (if $I$ may use such a term in reference to a racliate) and weaken the animals if eaten too frequently. On an average a penny or twopence a week is quite sufficient to supply all that is necessary, as a fragment can be cut off fish intended for one's dimner. The food should be chopped into very small pieces, and one of the size of a No. 1 shot, given with a pair of wooden forceps smaller than those at Fig. 7, to an Anemone which when expanded is of the size of a silver $3 d$. piece, and so in proportion. Fish, crustaceans, \&c., may lave larger pieces in proportion to their size, but it is better that they should be small. All food should be freshly killed, and never given in a decomposing state. Living and healthy slimps, form a most importint article of diet for many fishes, such as the Wrasses. It is curious to observe even in the lowly organised class of sea anrmones a certain amount of instinct. When one has been fed, the others in a Tank although closed at the time, will soon expand in anticipation of their morsel. Crustaceans and many fishes will, when romiciliated, rearlily take food from the hand of those accustomed to feed them, and I once had a tame mollusk (Nassa reticulata), the dog whelk, which exhihited this intelligence and always appeared with his long cylindrical proboccis carried aloft and waving to and fro, whenever there was any feeling going on. All butchers' meat, poultry, and cooked meat should be avoided. My friend Mr. S. Allport, records a remarkable instance where he gave a piece of cooked fowl to an anemone, which immediately died as from the effects of a poison. I have found by experience that when after feeding the animals in a Tank the water indicates by milkiness or slight smell, some amount of decomposition going on, a little of Condy's fluid introduced has a most satisfactory result, and almost immediately restores brilliancy and freedom from odour. It must, however, be done very cautiously, as its effects are detrimental to healthy vegetation. After feeding the good old proverb encegests rest-and I have but lithle more with which to troulile my hearers about the management of the Manine Aquarium.

One thing I must mention-and it is an of cration perhaps, a little troublesome, involving time and latience-cleansing. ()nes in the 
year, in late autumn, the Aquarium should be dismantled, except of course the rockwork-its living contents carefully provided for in vessels (temporarily), and the whole thing-slate, glass, rockwork, and shingle, thoroughly scrubbed with a brush, and rinsed again and again with fresh water before the sea-water is returned to the Tank. It is rather a tiresome process, but the stimulus to the increased health of its inhabitants will be an ample repayment of the trouble-besides fresh vegetation succeeds better when the decayed remains of a previous year's growth have been removed, and the surface of the rockwork presents a more favourable nidus for the attachment of the spores from newly introduced plants. A sponge dipped in fresh water and passed now and then over the water line on the glass in the Tank, will prevent the incrustation of saline particles, \&c., difficult to dislodge if left for a time. Persistently adherent vegetation may be removed by the application of dilute sulphuric acid,--taking care that it is applied carefully and the rockwork or glass well wasined afterwards. Mr. Gosse once told me a good story of an elderly lady acquaintance of his who had a Marine Aquarium, and whose views of cleanliness in its management carried her so far as to call forth the observation that "there is nothing for it but soap and water once a week!" Mr. Lloyd informs me that "so carefully balanced are the light, temper"ature, and air, in relation to the vegetation, animals, and water," that the Tanks in the Crystal Palace Aquarium do not require to be cleansed-that the supply of oxygen by artificial means is in fact, so great as, to use Liebig's famous expression "eremacausis," bum up all vegetation and decomposing matter, -and I am aware that some Aquarisists do not attempt the operation of cleansing in private Tanks, but my own experience is decidedly in favour of its being done as I have suggested once a year in the late autumn.

Here is a Scliedule of the present contents of my own Tank holding about 12 gallons of sea water:--

3 Minjil capito (Grey Mullet) 4 or 5 inches long.

3 Crenilulyns mestris (the Goldsinny), about the same size.

1 Blennius wholis (Smooth Blenny).

1 " Montupii (Montagu's Blenny).

2 Pulcemon servetus (Common Prawn); and,

5 species (numbering 8 intividuals) of Anemones. 
Here is another Schedule from a glass Aquarium-a confectioner's cake glass, which I have previously described-holding between one and two gallons of water:-

2 Symgnathus lumbriciformis (Worm-pipe fish).

1 Murcenoides guttata (Butter fish).

1 Lepidogasler bimaculatus (Two-spotted Sucker).

3 Echinus miliaris (Sea Urchin).

1 Asterina gibbosa (Starlet).

A mass of tube-worms (Serpula), numbering ten or a dozen.

Several tunicates, and 5 species (numbering 7 individuals) of Anemones. Microscopic life of all kinds is found, but of course I omit this. All the fishes in this Aquarium, it should be observed, are very small.

It is not too mucl to say that all these animals are maintained in as good health as it is possible to obtain within the limits of Aquaria of small size. Some of the radiates have been in my possession for years-two of them (Tealia crassicornis and Anthea cereus) are well known to Aquariists to be most difficult or almost impracticable to keep in health in a private tank. Some of the fishes (which include seven species) have been in captivity for eighteen months, and none less than four months, and they have grown appreciably. The blennies travelled by post from Cornwall last March in a tin box, packed with damp seaweed, and they have grown considerably since that time.

It must be always remembered by the Aquariist that it is not sufficient to keep his collection of animals in bare existence. It would be cruel to do so. They should present as nearly as possible the healthy appearance which they bear in their natural free state, possessing appetites to take the food offered to them, and performing the functions of reproduction-they will then be in a condition to be exhibited by the Aquariist with that satisfaction with which a horticulturist would show the treasures of a greenhouse, or the produce of a garden (in season) on which he has lavished care and attention.

My paper would perhaps be incomplete without some reference to the Marine Aquarium æsthetically and economically considered. A good Aquarium is an untiring and ever pleasing object of interest and study both to oneself and friends. Unlike a green-house or garden, its treasures are always the same-the animal flowers are ever 
howning-and the graceful nutions of the crustaceans and fishes may be watehed for hours together. When supplemented by a Microscope a new and inexhaustible field of observation and enquiry opens up to the mind-because in a healthy Aquarium microscopic forms of life are constantly being develuped from germs in the water, and many of the higher forms of marine life may be examined in situ. And what may be said of a private Aquarium, may be said of public Aquaria with far greater force. It cannot be doubted but that a public Aquarium successfully managed is one of the greatest triumphs of science, that lias ever been applied to the furtherance of the study of Natural History. When one looks back over the history of the Aquarium and remenbers its introduction as a fashionable amusement twenty or more years ago, when the genial artist. John Leech satirised it in Purch, among the follies of the clay, our times indeed have changed, now that Nuture, the most influential of scientific serials, records the additions to the Irighton Aquarium as regularly as the Morning Post chronicles the movements of Society. No one who ever sees that wonderful collection, or the smaller, Dut (to me as a Naturalist) still more efficient and unique one at the Crystal Palace, but comes away with his mind exalted by the contemplation of beings his remotest fancy never could have pictured in their living state; confined it is true, but free and active as in "the depths of the sea." To those who have not seen either, I say visit both. You will come away and wish you had such a collection in our good Townand wishing may lead to action, and help on our movement to establish one. The Marine Aquarium appeals to the two extremes of society - to the unlettered, who look with wonder aud curiosity on strangeness of form, and beauty of colour-and to the cultivated, who from a ligher point regard with profound interest, details of structure and affinities and analogies with beingrs of other worlds and times besides our own. The Marine Aquarium is at once a livingr Museum -a beantiful picture-a clnoice library! No cabinet collection of deied specimens can bring to view such instances, among a thousand others, as the graceful progress of the Pleuronectide (the flat fishes) or the weird form and muscular contractions of the cuttle-fish! No picture ever painted, can rival in colour the markings of the Wrassus, or the "living fire" (as NIr. Newman aptly terms it) of the eyes of the 
gemmeous Iragonet! No library on Zoology can give the Student a clear idea of the denizens of the deep from mere description, as can the contemplation of the actual living beings themselves. Doubtless as a utilitarian agency for the solution of undetermined points in Biology, the Aquarium is still in its infancy, though I cannot help thinking that if the successful. cultivation of some marine plants are combined with it, as I have shown that they can be even in a small Aquarium, it will be of immense value by supplying its inhahitants with natural food (which they do not under present circumstances obtain,) - they may breed freely in confinement,-and we may in some measure help to arrive at a solution of such problems as how to secure the proper development of those almost innumerable germs of food supply that are presented by sea fishes in general. For instance, the Turbot produces about fourteen millions of eggs annually, of which not one perhaps in ten thousand reaches maturity, nor one perhaps in a million finds its way to our tables! Our knowledge of the laws governing the movements-appearance and disappearance in certain localities-of the Herring and other fishes-their spawning and time of development, is still obscure, anci if we had light upon this subject, thousands of tons of valuable food would be available for us amnually of a most nutritions and palatable character. But apart altogether from such speculations as these, which some may consider visionary-but I, for one, do not, inasmuch as in consequence of the recent regulations as to Salmon fisheries it is evident that notwithstanding the enormously increased consumption, Salmon is, from its cheapness, at certain times of the year, within the reach of the artizan. But this is not our present question, the Marine Aquarium as a public Institution is established for purposes of amusement and instruction. As mankind becomes more highly educated, higher intellectual recreations will be not a luxury but a necessity, and as such the public Aquarium eminently ranks in our days. May the time come when the Marine Aquarium of Birmingham shall be an established fact, and take its stand with others of large Cities here and on the Continent, is a very earnest wish of mine, shared, I believe, by most of the Members of this Society. 


\section{POSTSCRIPT.}

\section{VASCULUM FOR COLLECTING MARINE ANIMALS.}

In the Zoologist for 1864, page 9,340, I described a newly devised Vascutum which I had in use for the collection and transmission of living marine animals from the coast. Since that time my friend, Mr. W. P. Marshall, has been good enough to take the subject in hand and has much improved upon the original design, which after long experience was found to be somewhat too heavy, and otherwise objectionable in consequence of the chipping off of the enamel with which the Vasculum was coated. I think it not inappropriate to append a description of this Vasculum-as kindly supplied by Mr. Marshall—to the foregoing paper, as it may be exceedingly useful for those who collect personally, or who require their specimens to be forwarded direct from the sea coast. It may not be generally known that most marine animals do better when packed in damp sea-weed than when transmitted in sea-water. All the sea-anemones and corals, all the echinoderms, many crustaceans, and several littoral species of fishes may be packed in this way. Mr. Lloyd, in a very interesting paper in the Zoologist for February, 1874, gave an elaborate account of the best modes of transmission of Aquarium animals, which may be read with advantage by all Aquariists.

The following is Mr. Marshall's description :-

"Vasculum or collecting-can for aquatic objects, of light construc"tion, convenient for carrying, compact when open for use, quite plain "and smooth, and free from any recesses in which small objects might "be lost, or dirt accumulated, and readily made clean and dry "after using.

"It consists of a square metal can (Fig. 9) with rounded corners, 6 "in. long, $4 \frac{1}{2} \mathrm{in}$. wide, and $6 \mathrm{in}$. high, with a flat lid having a perfor"ated centre for ventilation; the lid is without any lip or fastening, 
"and has a projecting hinge that allows it to hang close against the side "of the can when open; and the can has a square shaped wire handle "that falls down close to either side, and has a wood handle threaded "upon the centre portion, the same length as the can.

"The bottom half of the can forms a well for carrying living "animal and vegetable objects in water, and the upper" half is occupied "by a metal tray $3 \mathrm{in.} \mathrm{deep,} \mathrm{(Fig.} \mathrm{10)} \mathrm{that} \mathrm{fits} \mathrm{the} \mathrm{can} \mathrm{loosely,} \mathrm{and} \mathrm{is}$ "supported at each end by a narrow lip resting upon the top edge of "the can. This tray has a perforated bottom for drainage, and a vertical "tube $\frac{3}{4} \mathrm{in}$. diameter is fixed in the centre, having a funnel shaped top " $1 \frac{1}{2}$ in. in diameter level with the top of the can ; this gives access to "the well whilst the tray is in its place, and also serves as a ventilator" "for the well, and a handle for lifting the tray." Animals not requiring to be transmitted in sea-water may be packed in damp sea-weed and placed on this tray, where they are kept from being crushed, and the medium in which they are packed is constantly preserved moist, by the dashing up of the sea-water in the well, which water can be frequently changed during a long journey without much difficulty.

The Vasculum has been very efficiently and economically made of copper by Mr. T. M. Walker, 17 $\frac{1}{2}$ Lower Priory, and the Plating Company (Limited), S2 Lichfield Street, Birmingham, have successfully coatel it with their patent nickel deposit, which protects the metal from any action of sea water, and preserves every part perfectly bright and clear as silver-an immense advantage, as many delicate marine animals succumb under the effects of confinement where oxidation is going on from water coming in contact with iron, tin, zinc, or indeed with any metal, so far as my experience goes, -except nickel, which seems to be absolutely impervious to the action of sea water.

\section{LIST OF COLLECTORS, \&c. OF MARINE ANIMALS.}

As I have been frequently asked by friends and others, where and from whom they can obtain marine animals, I have thought it desirable to furnish the names of collectors of, and dealers in such animals.

If marine animals are wanted, it is best to order them in the late autumn or early spring months, because on account of the low tides 
prevailing, rarer and finer animals can be secured, and they will bear travelling far better when the temperature is low.

The following names of Collectors are principally taken from $\mathrm{Mr}$ Lloyd's Handbook, referred to in my paper.

Mr. E. Edwards, Vrondeg, Upton Park, Chester.

"J. Holwell, Morthoe, Ilfracombe.

:W. Jenkins, 2, St. Julian's Cottages, Tenby.

"R. Pile, Swan Street, Torquay.

"J. B. Randell, 19, Allez Street, Guernsey.

"C. Rogers, 18, St. Andrew Street, Plymouth.

"A. J. R. Sclater, Bank Street, Teignmouth.

"R. J. Smith, 25, St. Alban's Row, Weymouth.

"J. Thompson, 11, York Place, Southend, Essex.

Bimingham,

March, 1875. 

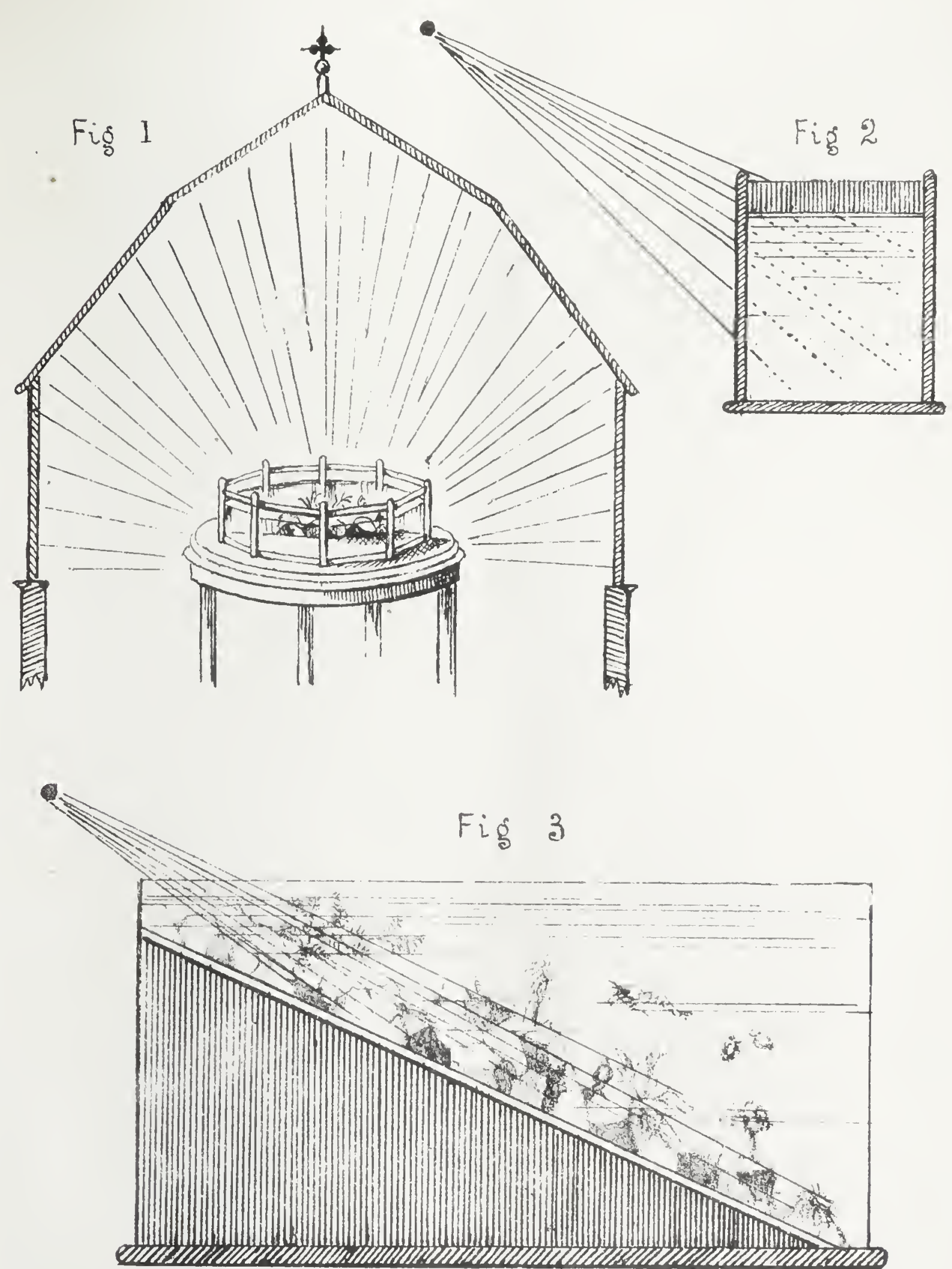

Fig 5

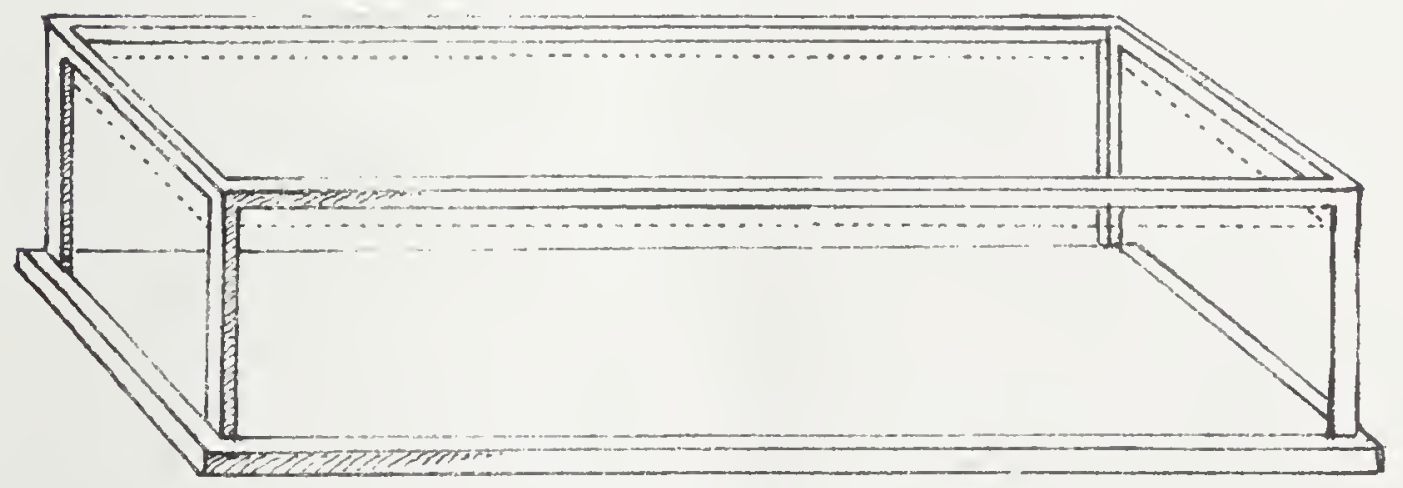





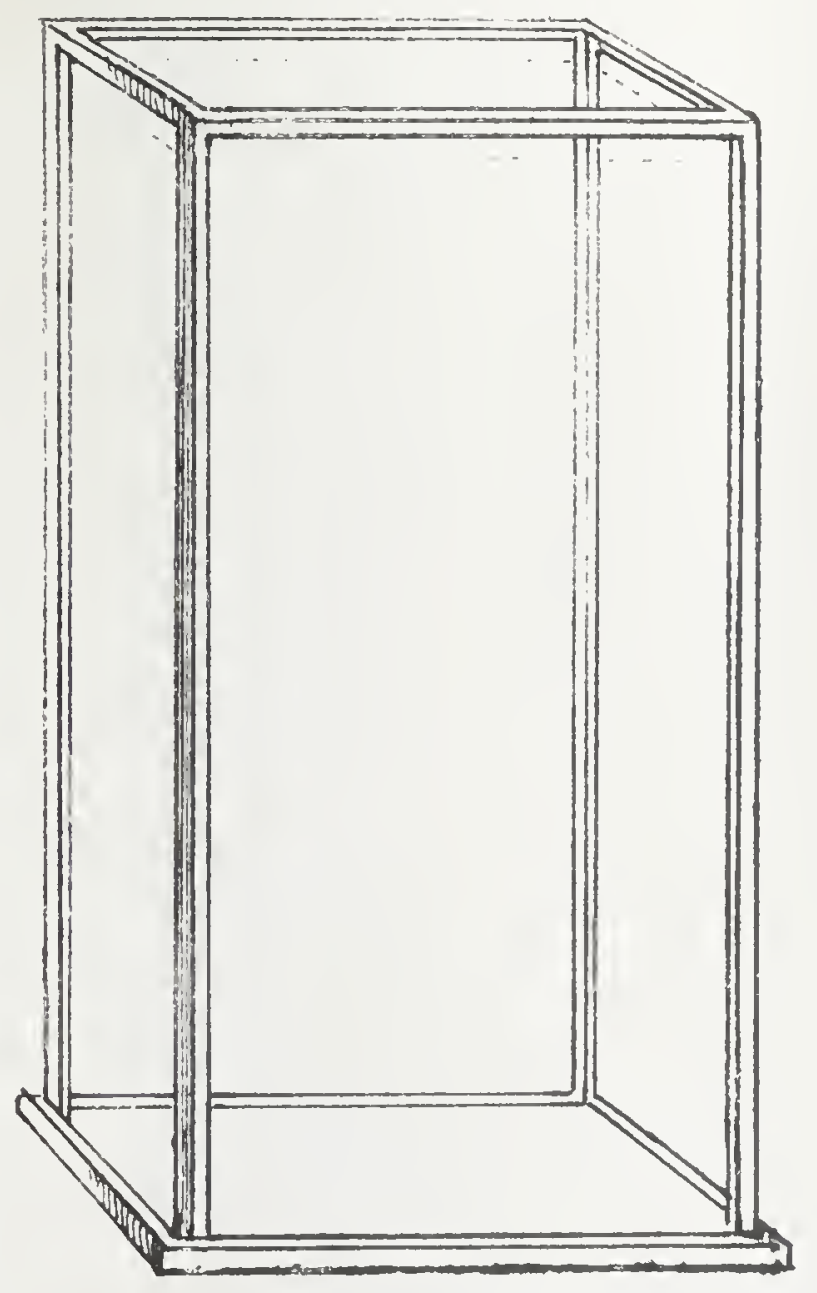

Fig $r$

Fig 8
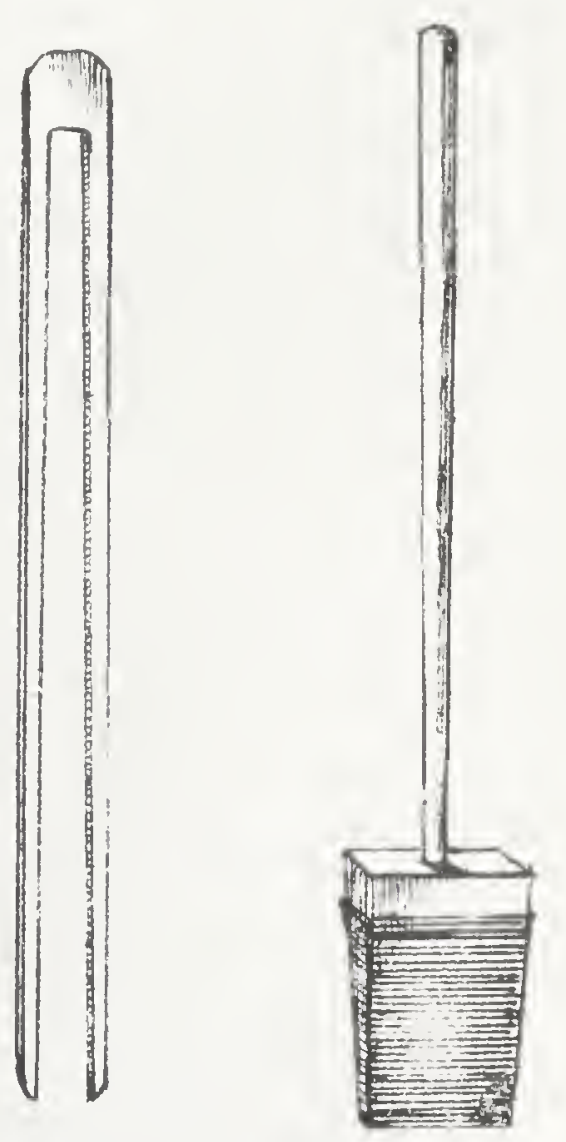

Fig 4

Fiǵ 10
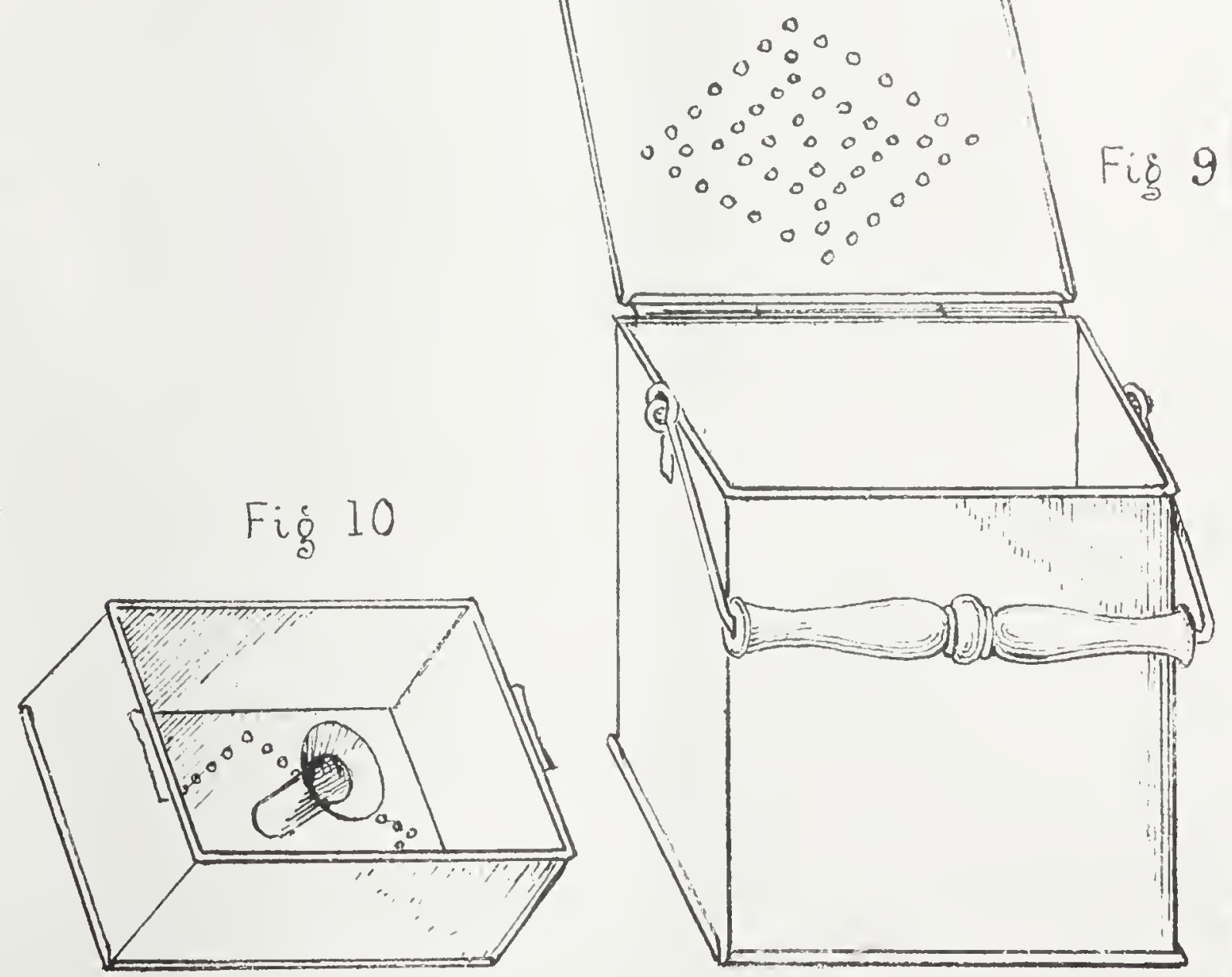



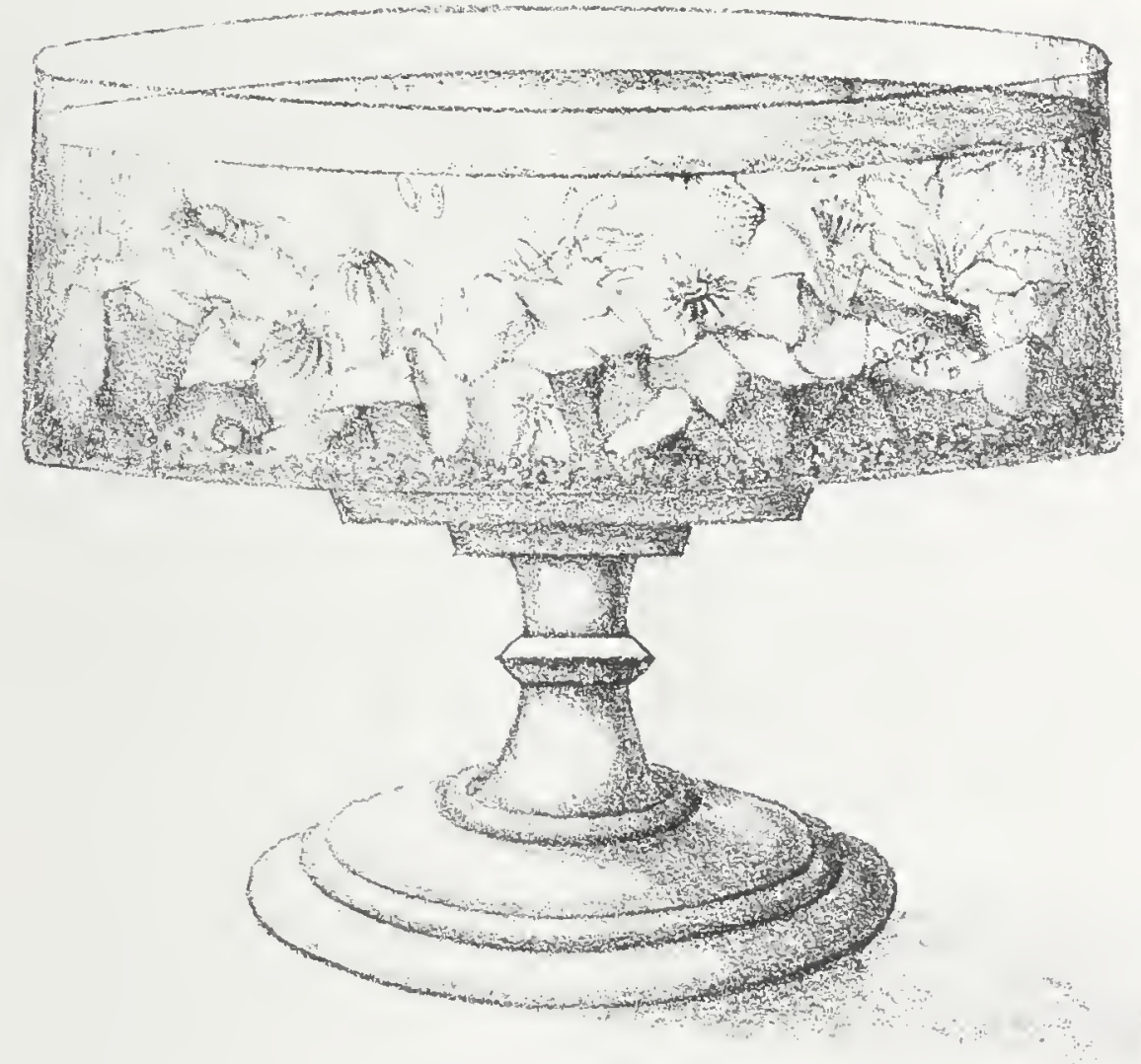

Fig 6 

. 
